\title{
Análise Sequencial de Políticas Públicas nas abordagens da Ciência Política e da Gestão (Management) 1
}

\section{Process Model of Public Policies in the Political Science and the Public Administration (Management) Approaches}

\author{
Dinah dos Santos Tinoco ${ }^{2}$
}

\begin{abstract}
Resumo
Dois principais modelos ou esquemas de análise se destacam na análise das políticas públicas: o modelo sequencial e sistêmico e o modelo estratégico. Este trabalho tem por objetivo compreender o modelo de análise sequencial a partir de duas principais abordagens identificadas na literatura francesa: a da ciência política, chamada politicas públicas, e a do management, ou gestão pública. Inicialmente, buscou-se estabelecer as origens e a caracterização dessas abordagens na França, seguida da utilização comparativa das principais categorias analíticas que guiaram a análise: problemáticas, processos e métodos. Os resultados mostraram que as duas abordagens apresentam diferenças e semelhanças, além de interdependências e interações. Uma diferença fundamental refere-se ao caráter normativo e prescritivo da abordagem do management, centrado nas "boas práticas", aspecto contestado pela abordagem da ciência política, cujos principais expoentes são acadêmicos preocupados principalmente com o conhecimento da ação pública, e não com a sua intervenção. A conclusão mostra que preceitos do new public management se impuseram às "ações públicas" contemporâneas, conduzindo à interação crescente entre as abordagens.
\end{abstract}

Palavras-chave: análise sequencial, políticas públicas, ciência política, management

\begin{abstract}
Two main analysis patterns stand out when it comes to analyzing public policies: the process model and the strategic model. This article aims to understand the process model through two major approaches identified by the French literature: the political sciences one, called public policies, and the public administration (management) one. At first, one sought to establish the origins and features of both approaches in France, ensued by a comparative use considering the following primary analytic categories: problems, processes and methods. Results revealed that both approaches present differences and similarities, as well as interdependences and interactions. One key difference is related to the normative and prescriptive character of the management, which is centered in "good practices". This last aspect is disputed by the political sciences approach, whose main representatives are scholars who worry particularly with the public action knowledge, not its intervention. Conclusion shows that the new public management principles imposed themselves on contemporary "public actions", which led to an increasing interaction between the two approaches.
\end{abstract}

Keywords: process model, public policies, political science, management

\footnotetext{
1 Uma primeira versão deste artigo foi apresentada no XXXII En ANPAD, Rio de Janeiro, de 6 a 10 de setembro de 2008.

2 Doutorado em Urbanismo - Universite de Paris XII (Paris-Val-de-Marne). Pos-Doutorado na Université de Versailles Saint Quentin en Yveslines, França. Professora no Programa de pós-graduação em Administração da Universidade Federal do Rio Grande do Norte. Endereço:Av. Praia de Genipabu 2100 Bloco IV, Apto 2002 Ponta Negra - Natal/Rio Grande do Norte - Brasil - CEP: 50054010 E-mail:dinahtinoco@uol.com.br
}

Artigo submetido em março e aceito em maio de 2009 


\section{Introdução}

As políticas públicas constituem atualmente na França uma disciplina científica pertencente ao campo da ciência política ${ }^{1}$, que, todavia, não monopoliza a análise das políticas públicas: essas integram um conjunto interdisciplinar muito mais vasto, que inclui a sociologia, a economia, o direito, a geografia, a psicologia, a gestão (o management ${ }^{2}$ ), entre outras disciplinas.

Dois principais modelos ou esquemas de análise podem ser destacados no estudo das políticas públicas: (a) $o$ modelo sequencial e sistêmico e (b) o modelo estratégico (Braud, 2006). Esses modelos estão diretamente relacionados às possibilidades de mudanças impingidas pela ação estatal no meio onde atua sob a forma de impactos ou efeitos das políticas públicas, pois "toda intervenção pública concreta é passível de provocar uma alteração no estado natural das coisas no âmbito da sociedade e pode estar atrelada a um ou vários fatos ou impactos" (Mény e Thoenig, 1989, p. 137). Em outras palavras, duas principais questões se colocam: (1) as políticas públicas constituem um vetor de mudança social? Ou (2) as políticas públicas apenas acompanham a mudança social?

No caso de o Estado constituir um agente privilegiado de mudança, encarregado de adotar uma postura próativa no desenvolvimento econômico com vistas a promover uma sociedade mais justa e integrada, a vontade política é determinante. Essa postura se defronta, todavia, com objeções múltiplas, como a herança institucional, processos decisórios, multiplicidade de atores e interesses envolvidos, lobbies, entre outros, que dificultam a implementação da política (Chevalier, 2005).

No caso de o Estado apenas acompanhar a mudança social, predomina uma visão incremental da política. Segundo Chevalier (2005, p. 386):

A visão incremental concebe, dentro dessa perspectiva, a ação pública como uma simples ação à margem, procedendo por imperceptíveis modificações, acompanhando as mutações lentas e progressivas que afetam o meio social: esta "gestão incremental" seria indispensável para permitir à sociedade evoluir sem grandes rupturas e sem romper com o consenso em torno das autoridades políticas [...] a ação pública se limitaria a registrar as mudanças sociais em curso para codificá-las $e$ eventualmente as acelerar, não para provocá-las.

O presente trabalho resultou de pesquisa bibliográfica realizada com o apoio do CNPq em estágio de pósdoutorado no exterior. O exame das literaturas da ciência política e da sociologia política produzidas na França, referentes à análise sequencial e sistêmica, explicita reiteradamente não compartilhar dos posicionamentos da abordagem do management sem deixar claros os aspectos divergentes. Enquanto isso, a abordagem do management, em geral, utiliza autores da ciência política e da sociologia sem tecer comentários sobre diferenças ou especificidades entre as abordagens.

Este artigo busca elucidar o modelo de análise sequencial e o faz a partir de duas principais correntes: a da ciência política, dita políticas públicas, e a do management, ou gestão pública ${ }^{3}$. Teve por objetivo compreender, em linhas gerais, a análise sequencial de políticas públicas no âmbito dessas duas abordagens e examinar as especificidades de cada uma, suas semelhanças e diferenças. Para tanto, buscou elucidar as questões de pesquisa seguintes: Quais problemas a análise sequencial e sistêmica visou responder no âmbito dessas duas abordagens? Como essas abordagens perceberam as políticas públicas? Quais as principais categorias analíticas por elas utilizadas? Como foram explicados os processos de formulação, decisão, implementação e avaliação de políticas públicas no âmbito dessas abordagens? Quais as suas principais contribuições e limites?

A abordagem da ciência política integra conteúdos organizados, em geral, em combinações transversais de conceitos e categorias analíticas. Originando-se das disciplinas confluentes com a ciência política (principalmente sociologia política), foi introduzida na França por um estudo homônimo de Yves Mény e JeanClaude Thoenig publicado em 1989 pela Presse Universitaire de France (PUF) sob a forma de um manual ${ }^{4}$, embora dois outros importantes estudos tenham sido publicados antes, na mesma década, visando compreender 
a ação do Estado: O Estado em Ação, de Bruno Jobert e Pierre Muller, publicado em 1987, e L'État au Concret, de Jean G. Padioleau, que data de $1982^{5}$.

Essa abordagem foi inspirada em teóricos americanos, já com forte tradição em estudos e pesquisas nessa área. Em seguida, recebeu a adesão de pesquisadores europeus, cientistas políticos, sociólogos de diferentes correntes teóricas, que passaram a referir-se aos conceitos e principais questionamentos desse manual nas suas análises, tal como a inversão efetuada pela questão As políticas públicas determinam a política? Até então, as políticas públicas eram vistas como dependentes da política. Uma intenção explícita dessa abordagem era aprofundar o conhecimento científico da ação do Estado, a qual se caracteriza pela arte de colocar boas questões que devem ser respondidas e explicadas pelos fatos, ou seja, pela pesquisa (Mény e Thoenig, 1989).

A abordagem do management surgiu na França muito antes da outra, chamada políticas públicas, por volta dos anos 1970, se for levada em consideração a institucionalização de órgãos de pesquisa e instituições universitárias voltadas para a profissionalização da disciplina. Caracteriza-se pela pesquisa de instrumentos, métodos e técnicas para promover a eficiência e eficácia das organizações e de suas políticas e atividades, dessa forma, apresenta um caráter normativo e pragmático. Tem recebido também a contribuição de outras disciplinas como o direito e a economia. Em muitos aspectos, suas análises compartilham de contribuições teóricas utilizadas pela análise denominada políticas públicas.

A gestão pública pode ser apreendida em duas principais vertentes:

- No sentido amplo, contempla as políticas públicas associadas às organizações públicas.

- No sentido estrito, refere-se apenas às organizações públicas (Gibert, 2002).

Diversos autores (Gibert, Santo e Verrier, Thoenig) consideraram a vertente do management em sentido amplo, ou seja, conceberam o management numa visão integrada na qual políticas públicas e organizações devem ser analisadas em conjunto ${ }^{6}$.

O presente artigo foi dividido em três principais seções: a primeira visa observar as origens de cada uma das duas abordagens; a segunda pretende expor, em linhas gerais, as problemáticas que essas abordagens procuraram inicialmente responder, bem como os seus principais conceitos; a terceira expõe os métodos e categorias analíticas por elas utilizadas; seguidas de uma conclusão. As inter-relações, especificidades, concorrências e competições entre as abordagens foram destacadas e, na medida do possível, analisadas.

\section{Origens, relações e interpenetrações das abordagens}

A análise das políticas públicas originou-se nos países anglo-saxões e esteve inicialmente, nos Estados Unidos, baseada na noção de governement, visando contribuir para a eficácia do sistema político que então governava aquela sociedade. Nesse sentido, vale ressaltar que desde o século XIX o governo americano de Woodrow Wilson buscava formas de eliminar a corrupção, logo, de melhorar o funcionamento do aparato políticoadministrativo estatal (Benh, 1998).

As preocupações com a eficácia e a eficiência eram constantes no início do século XX, tanto no que se refere às empresas privadas em geral quanto às administrações públicas em particular. Taylor pesquisava sobre a organização científica do trabalho para estabelecer "o melhor método" (the one best way) para o desempenho das tarefas, e Max Weber concebia a burocracia como um meio organizacional de gestão da sociedade devido às suas características de racionalidade, impessoalidade e profissionalismo.

É importante observar as condições que respaldaram a emergência da análise de políticas públicas nos Estados Unidos e na França para melhor perceber os principais aportes e contribuições dessa análise ao desenvolvimento acadêmico e profissional das duas abordagens aqui em enfoque.

O desenvolvimento nos Estados Unidos de uma policy science (ciência das decisões e das políticas públicas) recebeu o apoio de organizações de financiamento de pesquisa, inclusive privadas, desde os anos $1920^{7}$. As repercussões da crise econômica de 1929 e a Segunda Guerra Mundial contribuíram para a intervenção 
econômica crescente do Estado americano e para regulações sociais com objetivos pontuais e pragmáticos. Nesse contexto, a filosofia pragmática americana se expandiu e, juntamente com ela, o viés utilitarista de "ajuda à decisão". Em vez de equipes universitárias, predominavam então os escritórios de estudos, bureaux d'études, e os experts individuais. Foi somente no pós-guerra que os estudos sobre gestão pública e pesquisas administrativas de inspiração universitária contribuíram naquele país para o surgimento dos departamentos acadêmicos de ciência política, convivendo também com outras correntes disciplinares como a psicologia, a sociologia e a economia, voltadas principalmente para as pesquisas sobre a decisão (decision making) (Gaudin, 2004, p. 116).

Na Europa, no pós-guerra, a interdisciplinaridade era menos presente, as disciplinas jurídicas e a economia política concentraram as análises então predominantes sobre a ação pública e o Estado intervencionista (Gaudin, 2004). Até a noção de políticas públicas teve dificuldade de aceitação, pois foi o conceito de Estado desenvolvido por Hegel, Marx e Max Weber que se impôs devido à forte tradição jurídica e filosófica do país (Muller, 2003).

A doutrina da gestão pública (management public) na França originou-se no mundo empresarial apresentandose inicialmente muito próxima às especialidades funcionais das empresas. A transposição de técnicas e métodos de gestão das empresas privadas, consideradas eficazes para as organizações públicas, expandiu-se sob a égide do Estado Providência ${ }^{8}$, exigindo o desenvolvimento de uma ciência das organizações públicas para fazer face aos problemas complexos de gestão (Bezés, 2005, apud Gibert, 1980). Além da transferência dos saberes do setor privado para o setor administrativo público, ocorreu também a transposição de metodologias e métodos de ensino dos Estados Unidos para a França (Bezés, 2005, apud Thoenig, 1976). Contudo, a França foi marcada por uma forte essência religiosa ${ }^{9}$, diferentemente dos países anglo-saxões, onde as associações entre gestão pública e gestão privada ocorreram sem problemas no universo simbólico das pessoas (Santo e Verrier, 1997).

Segundo Bezés $(2005)^{10}$, foi nos anos setenta e oitenta do século XX que foram desenvolvidas as condições para a emergência e promoção da gestão pública (management public) em âmbito organizacional e doutrinário na França. Duas organizações criadas nos anos 1970 destacaram-se nesse sentido: o Centre d'Enseignement du Management Public (Cesmap) e o Centre Supérieur de Formation en Management (CSFM) ${ }^{11}$. Além dessas organizações, as grandes escolas de gestão passaram a se dedicar também ao ensino do management public, a exemplo da grande escola de estudos comerciais - Hautes Études Commerciales (HEC). Desde o início, o ensino ministrado nessas organizações e escolas de gestão recebeu forte influência americana. A análise das políticas públicas galgou um espaço prioritário no âmbito do management nesse período, pois passou a constituir um "saber útil" para os especialistas e práticos do mundo empresarial, ao mesmo tempo que permitiu uma maior compreensão do funcionamento do aparato político-administrativo em um contexto favorável à institucionalização da avaliação de políticas públicas. Esses especialistas encontraram um espaço de inserção profissional importante na esfera estatal.

Porém, o ensino superior da gestão pública (management public) permaneceu restrito nos anos $1980^{12}$. Um conjunto de restrições impediu o desenvolvimento acadêmico do management. Por um lado, a École National d'Administration (ENA) obteve o monopólio legal da formação da alta função pública generalista a partir de 1982 com a reforma do estatuto da função pública d'Anicet le Pors ${ }^{13}$. As instituições precursoras como o antigo Cesmap, que a partir de 1982 passou a ser denominado Institut de Management Public (IDMP), direcionou-se para o mercado crescente de consultorias, o que, segundo Bezés (2005), contribuiu para a "balcanização" do management.

Essa nova gestão pública tem um novo expoente: a tecnocracia estatal que, em vez de pesquisadores universitários, agora são os altos funcionários que participam de instâncias como comissões e missões encarregadas da reforma do Estado e aparecem como "mediadores", tradutores da nova gestão pública na categoria de experts. Esses integram redes transnacionais, sejam instituições européias, organizações do tipo OCDE, Banco Mundial ou gabinetes de consultorias que elaboram e difundem "the best practices" (as boas práticas $)^{14}$. Essas redes transnacionais constituem fóruns de discussões, trocas de experiências e orientações para a ação (Bezés, 2005). 
O management é uma ciência, uma disciplina ou apenas um conjunto de métodos de gestão? Essa discussão que mobilizou professores de disciplinas jurídicas e impunha resistência à doutrina do management na França, apresentou uma situação peculiar baseando-se principalmente em métodos de gestão, análises de políticas públicas e avaliação e, sobretudo, encontrava-se em concorrência com as disciplinas jurídicas que se destacavam quanto à formação e os concursos dos funcionários do Estado. Essa situação foi muito diferente da trajetória do management na Grã Bretanha e nos Estados Unidos, chamada de neotaylorismo sob a influência das teorias econômicas (Pollitt, 1990, apud Bezés, 2005).

Por sua vez, a abordagem chamada políticas públicas respaldou-se na bibliografia americana em seus estudos pioneiros, como o de Charles Jones de 1970, que via a política pública como uma sequência racional e linear de decisões ${ }^{15}$. Apenas em 1989, o livro Politiques Publiques, de Yves Mény e Jean Claude Thoenig, lançou as bases da abordagem de mesmo nome na França, a qual defendia a necessidade do analista fazer questionamentos e recorrer à pesquisa empírica para confirmar ou negar as suas hipóteses. Para tanto, recorreu ao que os autores chamaram de "caixa de ferramentas" (boite à outils) para se referir às formas de raciocínio mais utilizadas com vistas ao estudo da ação do governo, os recortes das realidades empíricas, suas reconstruções e interpretações (Mény e Thoenig, 1989, p. 123).

Ao longo dos anos, verificou-se a desmistificação das ações do Estado. Três rupturas foram identificadas na análise das políticas públicas por Lescoumes e Le Galès (2007, p. 16): (i) a ruptura com o voluntarismo político; (ii) a ruptura com a unicidade do Estado; e (iii) a ruptura com o fetichismo da decisão.

A primeira ruptura refere-se ao fato de que nem sempre as decisões tomadas pelos homens políticos têm efeitos práticos; algumas têm apenas efeitos de fachada, outras se defrontam com dificuldades de implementação, seja em relação ao poder discricionário dos atores, aos processos caóticos ou às consequências inesperadas.

A segunda ruptura diz respeito ao mito da homogeneidade do Estado. Pesquisas da sociologia das organizações têm demonstrado a heterogeneidade de grupos, redes, interesses e estratégias que interferem no âmbito do Estado em função de suas lógicas específicas e meios de ação.

A terceira se relaciona com o fetichismo da decisão, as escolhas antes centrais, abriram espaço para ações coletivas, não decisões, processos contraditórios, dispersos, invisíveis.

Embora esses aspectos contestem o voluntarismo político que marca em princípio o modelo sequencial e sistêmico de análise de políticas públicas, esse modelo ainda parte de uma visão centrada no Estado e no voluntarismo de sua ação, só que não mais de forma centralizada: governantes e dirigentes estão em interação com outros atores, processos, instrumentos e instituições que atuam nas diversas fases da política pública, ou melhor, da "ação pública". Essa terminologia tem substituído a primeira, visto que uma grande diversidade de atores públicos e privados interagem com o Estado mediante diferentes formas de mobilização (redes, fóruns, entre outros) em processos de concertação e coordenação sob o âmbito da "governança":

[...] Governança não é sinônimo de governo. As duas noções se referem a comportamentos expressando uma vontade, às atividades guiadas por um objetivo, ao sistema de regras. Mas a idéia de governo implica uma autoridade oficial, dotada de capacidade de polícia, garantindo a boa execução da política adotada. A governança, ela cobre atividades sustentadas por objetivos comuns; esses objetivos podem se inscrever ou não em mecanismos legais e formais de responsabilidade, eles não requerem necessariamente poderes de polícia para ultrapassar as desconfianças e obter a aplicação da norma. Em outras palavras, a governança é um fenômeno mais amplo que o governo [...] (Roseneau, 1992, apud Defarges, 2006, p. 32).

Mesmo que a perspectiva centrada nos atores sociais esteja em evidência é preciso não esquecer que as "ações públicas" apresentam grande diversidade e que algumas ações são conduzidas e fortemente permeadas por atores não estatais enquanto outras ainda se encontram centralizadas no Estado e em suas instituições. 


\section{Problemáticas e conceltos do modelo de análise sequencial nas duas abordagens}

Os autores aqui destacados (Mény e Thoenig), pioneiros da abordagem chamada políticas públicas na França, foram guiados por questões clássicas como as seguintes: $O$ que produzem os que nos governam? Para que resultados, através de que meios? As políticas públicas eram geralmente vistas como variáveis dependentes de outros fatores políticos ou econômicos. Eles realizaram então uma inversão, a título de hipótese, ou seja, observar as políticas como variáveis independentes. Para tanto, formularam a seguinte questão: as políticas públicas determinam a política?

A reversão dessa questão permite, segundo os autores, proceder a uma mudança de perspectiva que fazia da política (policy) um produto (output) do sistema político, permitindo elucidar a ação de atores essenciais, como o Estado, as instituições, os agentes locais e internacionais, entre outros, bem como seus métodos, concepções, instrumentos e estruturas. É numa perspectiva de pesquisa científica que essa abordagem se coloca, como é aprofundado adiante neste texto.

A abordagem do management parte de um problema concreto: a crise dos serviços públicos entre as duas guerras mundiais, a qual se agravou a partir dos anos 1960 por pressões externas que estiveram na origem de uma crise de legitimidade da burocracia e dos instrumentos de gestão utilizados pelo Estado (Santo e Verrier, 1997). Essas pressões eram de ordem econômica e orçamentária (intervenções estatais crescentes e diminuição das alocações orçamentárias); pressões industriais (tecnologia pesada como telecomunicação, aeroespacial e informática); e pressão dos usuários (pela comparação entre os serviços públicos e privados das escolas, hospitais, entre outros). Assim, o management teve como objetivo a "ajuda a ação", buscou encontrar os melhores métodos, os instrumentos apropriados, para fazer mais e melhor. Dessa forma, procurou responder a um objetivo utilitário: o de melhorar o funcionamento do aparelho administrativo do Estado, ou seja, a pesquisa da eficiência e da eficácia.

Os principais autores, tanto da abordagem da ciência política quanto da abordagem do management, elaboraram definições semelhantes, nas quais o governo apresenta ainda um papel central na produção das políticas públicas. Esse aspecto pode ser observado nas definições que se seguem:

Segundo a abordagem políticas públicas, no quadro conceitual erigido pelos autores: "uma política pública se apresenta como um programa de ação governamental em um setor da sociedade ou em um espaço geográfico [...]" ou ainda "as políticas são atos, e não atos empreendidos por uma autoridade pública face a um problema ou em um setor de sua competência" (Mény e Thoenig, 1989, p. 130).

$\mathrm{Na}$ perspectiva do management: "Uma política pública pode ser definida como a soma das ações empreendidas por uma autoridade pública com vistas a resolver um problema ou a manter uma situação satisfatória, em um domínio no qual essa autoridade é ou se vê competente” (Santo e Verrier, 1997, p. 88).

Aspectos como a centralidade e o voluntarismo do governo na produção das políticas públicas, que essas definições permitem vislumbrar, têm sido questionados atualmente, como já foi observado, em razão da participação crescente de outros atores, governamentais ou não, na formulação, decisão e implementação das políticas públicas, das enormes dificuldades da implementação que muitas vezes inviabilizam a execução da política, dos efeitos de fachada que o anúncio da política provoca sem que haja intenções reais de mudança (Lascoumes, Le Galés, 2007).

Massardier (2003, p. 1) também defendeu o uso da expressão ação pública e afirmou que as autoridades públicas não possuem mais o monopólio da fabricação das políticas públicas; pelo contrário, atuam com uma multiplicidade de atores, que projetam suas próprias finalidades no processo de elaboração das políticas públicas, o que conduz as autoridades públicas a estabelecerem acordos, negociações e contratos com esses diferentes públicos. A chamada ação pública inclui um jogo de atores muito mais vasto que o anterior, bem como novos processos, instrumentos e organização multiníveis, isso se deveu ao processo de descentralização instaurado a partir de 1982 na França, que passou a valorizar os níveis intermediários de governo baseados na noção de território. 
Lamarque (2004, p. 54) estabeleceu uma outra distinção ao conceito de ação pública assimilando-o a diferentes níveis de formalidades:

Ao invés de política pública, parece então mais pertinente falar de ação pública: essa formulação mais neutra permite englobar as formas mais elaboradas e complexas (as políticas) e os modos de intervenção menos formalizados (um procedimento) passando por programas concebidos para colocação em prática de sua própria avaliação.

A seção seguinte visa destacar os principais métodos e as categorias analíticas mais utilizadas pelo modelo sequencial de análise no âmbito das duas abordagens aqui em foco.

\section{Métodos e categorias analíticas do modelo de anállse sequencial nas duas abordagens}

Entende-se por método a referência ao estilo de análise, aos raciocínios e à relação entre as questões de pesquisa colocadas e os fatos observados no terreno da pesquisa (Mény e Thoenig, 1989).

Segundo Mény e Thoenig (1989, p. 12), a abordagem políticas públicas pode ser definida como campo e como método. O campo do trabalho governamental pode informar sobre a emergência e a natureza do Estado, a essência da política ligada à luta pelo poder e a ação pública, além do impacto da intervenção pública na sociedade. O método ou conjunto de métodos, permite que a ação pública seja decomposta em suas atividades distintas e analisadas.

Essa abordagem recorre a uma espécie de "caixa de ferramentas" (boite à outils), que contempla os modos de raciocínios mais utilizados para estudar as ações governamentais, ou seja, a "caixa preta" do Estado, a qual é preciso adentrar para desvendar.

A política pode ser vista (Mény e Thoenig, 1989, p. 152) como um sistema de ação pública, composto de atores, atividades e processos:

a) Quanto aos atores, as autoridades governamentais são centrais, mas coexistem com outros atores com os quais estabelecem relações de interdependência a respeito de instituições formais e informais. Esse aspecto tem apresentado uma complexidade crescente devido à maior incorporação de novos atores em todas as etapas da ação pública.

b) No que se refere às atividades, uma política é um conjunto de atos e não atos — quando a autoridade pública se recusa a agir - tanto materiais quanto imateriais, ou seja, simbólicos, como os discursos.

c) Os processos se referem às fases da política, ou seja, às etapas por ela contempladas, desde a identificação de um problema até a sua colocação na agenda, à escolha de soluções e ao tratamento a serem dados ao problema, à implementação das ações, visando a sua solução ou a sua diminuição e à avaliação das ações postas em prática.

O modelo de análise sequencial da ciência política busca compreender a atividade governamental com a ajuda da análise do conteúdo da política, no que se refere aos produtos ou resultados que devem ser por ela alcançados. A política integra um quadro geral, não pode ser vista como um ato isolado, mas como atos articulados em torno de eixos específicos. A ação da política afeta o meio social, de indivíduos, de grupos e instituições que integram diretamente ou indiretamente seu campo de ação. A política deve contemplar com a sua ação uma "teoria da mudança social", que significa uma relação de causa e efeito (Mény e Thoenig, 1989, p. 140). Estudos prévios são então necessários para estabelecer os efeitos de ligação entre as políticas, os efeitos perversos e, logicamente, os efeitos procurados.

Um aspecto relevante a observar é que a análise sequencial, tanto da abordagem da ciência política quanto do management, vê a ação pública como um sistema integrado por um duplo processo:

1. De uma parte, a gestão interna se refere aos meios (inputs) empregados pelas organizações públicas permitindo a elas obterem a eficiência e eficácia de suas realizações (outputs). 
2. De outra parte, as realizações, que podem ser entendidas como as políticas públicas postas em prática, vão provocar impactos ou efeitos (outcomes) junto aos grupos sociais, o que permite também apreciar a eficiência das realizações, mas desta vez junto ao público contemplado pela política (Patrick Gibert, 1988 apud Santo e Verrier, 1997, p. 111).

Assim, a análise de sistemas serviu de base para o estabelecimento de relações entre os elementos que integram o sistema e o ambiente.

Em relação às técnicas utilizadas, a análise sequencial da abordagem denominada políticas públicas destacou: análise de conteúdo, pesquisa documental, realização de entrevistas e aplicação de questionários e observação participante. As inovações são modestas mesmo em termos analíticos e conceituais, sendo as políticas públicas vistas como fenômeno político, contando para tanto com o aporte da sociologia e da ciência política, teoria das organizações, estudos da decisão, aos quais vieram se juntar aspectos econômicos, jurídicos e tecnológicos (Mény e Thoenig, 1989, p. 124).

A análise sequencial da abordagem management, ou gestão pública no sentido amplo, nega que seus instrumentos possam ser utilizados de maneira aleatória, como foi explicitado na abordagem da ciência política.Segundo Santo e Verrier (1997), o management não pode ser reduzido a uma caixa de ferramentas onde os responsáveis escolheriam de forma indiferente uma contabilidade analítica, um sistema de informação, uma comunicação externa ou um "quadro de bordo" (tableau de bord). O management, segundo esses autores, é a "colocação em perspectiva estratégica desses instrumentos".

Os estudiosos e teóricos da análise sequencial no âmbito do management têm se dedicado mais à compreensão das organizações, sejam elas privadas ou públicas, que ao estudo das políticas públicas, essas são menos estudadas nesse campo disciplinar. O postulado de partida dessa abordagem refere-se à analogia entre os problemas de gestão de todos os tipos de organização independente das suas finalidades (Gibert, 2002, p. 2). As novidades - quanto aos processos, métodos, princípios de ação, instrumentos de gestão — desenvolvidas inicialmente nas empresas são transferidas sob a forma de "transferência de tecnologia" (transfert de technologie) para as organizações públicas. Todavia, um problema se coloca: os limites impostos por essa transferência, devido às diferenças entre as finalidades das organizações privadas e públicas, que podem acarretar especificidades em termos de gestão. "[...] o management privado é orientado para a performance econômica tal como ela é determinada sobre os mercados, enquanto o management público é orientado pelo interesse público tal qual ele é determinado nos fóruns políticos" (Li Lynn, 1981, apud Gibert, 1996, p. 23). Embora as finalidades das empresas privadas sejam diversificadas, a exemplo da maximização da taxa de lucro, entre outras, subjetivas aos seus membros, a empresa é introvertida, guiada por variáveis internas e finalizada sobre si mesma. A organização pública, pelo contrário, é extrovertida, finalizada por ações que lhe são externas, como a vontade de mudar o seu meio ambiente ou de preservá-lo em caso de ameaça.

A análise sequencial da abordagem do management referente às políticas públicas

diz respeito ao estudo das condições concretas nas quais as autoridades públicas empreendem ações visando à mudança (ou à preservação) de certas características da sociedade desde a inscrição na agenda do governante de uma situação que causa problema até a possibilidade de realização de uma avaliação (ex-post) da política considerada (Gibert, 2002, p. 2).

Gibert $(2002$, p. 3) propôs a integração das organizações e das políticas públicas, designada por ele management public au sens large (gestão pública no sentido amplo): "Utilização profissionalizada dos aportes das ciências sociais, políticas e econômicas - com a mediação ou não dos métodos de gestão - com vistas a melhorar a performance das políticas públicas e para tanto a das organizações públicas".

Santo e Verrier (1997) defenderam igualmente uma análise integrada das organizações públicas através das suas atividades, pois, segundo esses autores, uma organização com baixo nível de performance não pode assegurar políticas públicas dotadas de eficiência e eficácia. As atividades, segundo os citados autores, são constituídas de um conjunto de tarefas que devem atender a alguns critérios, tais como: serem realizadas por indivíduos ou grupos, recorrerem a um saber específico, serem homogêneas quanto aos custos e performances, 
permitirem fornecer um "output" a um cliente externo a partir de um conjunto de "inputs". Dessa forma, tanto as atividades diretamente ligadas às políticas públicas quanto às demais atividades desenvolvidas pelas organizações públicas podem ser incluídas nessa análise.

Em relação às técnicas utilizadas, a abordagem do management destacou a análise de dados, a econometria, as monografias, as entrevistas e a análise de conteúdo, bem como o uso de técnicas e instrumentos das ciências sociais, principalmente quanto às fases da política pública, especialmente no que se refere à avaliação (Santo e Verrier, 1997, p. 112).

O item que se segue aborda as fases das políticas públicas no modelo de análise sequencial referente às duas abordagens destacadas. Essas variam muito de um autor a outro embora suponham, em geral, uma ordem linear e sequencial, raramente obedecida na prática.

\section{Análise sequencial: as fases da política pública}

As políticas públicas têm sido observadas como um processo de racionalização composto de fases ou etapas que têm constituído um aspecto heurístico e didático para a sua compreensão. Todavia, isso não significa que a ordem das etapas seja sempre respeitada, mas permite esclarecer algumas das múltiplas operações que integram o processo (Braud, 2006).

Esse processo, ao qual a política pública está atrelada, refere-se principalmente a uma perspectiva analítica hierárquica, a qual vê o governo como exercendo um papel central na seleção dos problemas, colocação na agenda, implementação e avaliação. Ao contrário da perspectiva analítica da "ação pública", que reconhece o papel de múltiplos atores de níveis diversos, inclusive territoriais, de âmbito privado e público em parcerias e outras formas de cooperação e negociação sob a forma de redes, entre outras.

Diversas análises questionam a racionalidade e a linearidade da decisão na política pública, como Sfez (1993), que a vê como proveniente de decisões rotineiras, coletivas, pouco coordenadas e portadoras de interesses múltiplos. Outros vêem a decisão como uma "anarquia organizada" onde os problemas, as ocasiões de escolha, os atores e as soluções interagem de forma mal organizada e pouco coerente (Lascoumes, Le Galés, 2007, p. 52, citando March e Olsen, 1972).

Vale ressaltar que há atualmente uma pluralidade de abordagens possíveis que fogem a essa perspectiva faseológica. Todavia, a análise sequencial nas duas abordagens aqui contempladas considera a política pública como um processo composto de fases ou etapas, embora os autores reconheçam que a sequência das etapas nem sempre é obedecida.

O quadro seguinte apresenta as fases das políticas públicas segundo a análise sequencial no âmbito das duas abordagens aqui destacadas. A abordagem da ciência política dividiu esse processo em seis fases; a do management a dividiu em sete. Algumas fases se assemelham nas duas abordagens: a fase da identificação de um problema na abordagem políticas públicas deixa subtendido que o problema deve ter sido inscrito previamente na agenda do governo. A fase de formulação de uma solução ou de uma ação (abordagem políticas públicas) parte do princípio de que um diagnóstico deve ter sido efetuado. Pode-se supor que essa fase corresponde à fase de determinação dos objetivos na abordagem do management. A aplicação da ação (abordagem políticas públicas) corresponde à implementação, ou mise en oeuvre (abordagem gestão pública). Essa fase é essencial à compreensão de uma política pública mesmo que ela tenha ficado muito tempo relegada a segundo plano dada a importância que era até então atribuída à tomada da decisão. A implementação se defrontou muitas vezes com a constatação da ineficiência, ineficácia e falta de efetividade das ações públicas do Estado Providência, provenientes do alto custo dos resultados obtidos, da discrepância entre os resultados obtidos face aos resultados propostos, bem como das dificuldades de aplicabilidade da política, tais como a demora da promulgação de decretos, impossibilitando a implantação das ações votadas, entre outros problemas. A única fase que não encontra correspondência na abordagem das políticas públicas é a fase de "avaliação a priori". Presente apenas na abordagem do management, essa fase reveste-se de grande importância, pois referese aos meios a serem mobilizados para obter os resultados desejados. É provável que a sua ausência na 
abordagem políticas públicas se deva ao caráter prospectivo que ela encerra, visto que a avaliação a priori busca a relação ótima entre meios e resultados. Assim, essa fase deve ser experimentada e avaliada antes da decisão de implementação para assegurar a eficiência e eficácia da política.

Todavia, como já foi aqui observado, as políticas públicas, em geral, não obedecem a essas fases de forma sequencial e linear, pelo contrário, os limites dessa abordagem sequencial têm sido continuamente postos em evidência, como observado por Muller (2003), que destacou que a ordem das etapas pode ser invertida, por exemplo, a tomada de decisão pode preceder à definição do problema. Outro aspecto a ser levado em consideração é a dificuldade da identificação das etapas. Por exemplo, quando é possível considerar que uma política resolveu um problema e, portanto, a ação deve ser terminada?

Para Muller (2003), as questões suscitadas pelas ações dos diferentes atores em relação a uma determinada política podem contribuir ao esclarecimento da mesma. E preconiza, seguindo E. Monnier (1992), que é preferível considerar uma política como um conjunto de sequências paralelas agindo umas sobre as outras, em mudanças contínuas, que como sequências sucessivas e lineares. Todavia, o caráter heurístico dessas fases da análise sequencial supera as suas dificuldades e insuficiências, pois busca identificar os processos, atores e instituições que se apresentam vinculados a cada uma das fases da política pública. 


\section{Quadro - Análise Sequencial de Políticas Públicas segundo as suas Fases e Abordagens}

\begin{tabular}{|c|c|}
\hline Abordagem Políticas Públicas & Abordagem Management Público \\
\hline & $\begin{array}{l}\text { Inscrição de um problema na agenda } \\
\text { Elementos desencadeadores, inscrição aleatória } \\
\text { (pressão dos acontecimentos fortuitos, tipo } \\
\text { inundações, secas, etc.) ou programática (integra o } \\
\text { programa do governo) }\end{array}$ \\
\hline \multirow[t]{2}{*}{$\begin{array}{l}\text { Identificação de um problema } \\
\text { Percepção dos acontecimentos, definição de um } \\
\text { problema, agregação de interesses, organização das } \\
\text { demandas, representação e acesso às autoridades } \\
\text { públicas - demanda de ação pública. }\end{array}$} & $\begin{array}{l}\text { Identificação de um problema } \\
\text { Identificação das causas, reconhecimento das } \\
\text { ideologias como filtros para a identificação, o poder } \\
\text { dos símbolos, a adequação dos discursos - a } \\
\text { identificação facilita o diagnóstico. }\end{array}$ \\
\hline & $\begin{array}{l}\text { O diagnóstico } \\
\text { Anterior à busca de soluções, as boas questões } \\
\text { contribuem para a busca de soluções adequadas; } \\
\text { deve ser feito por uma entidade interna ou externa } \\
\text { independente - integra a definição da política } \\
\text { pública. }\end{array}$ \\
\hline $\begin{array}{l}\text { Formulação de uma solução ou de uma ação * } \\
\text { Elaboração de respostas, estudo de soluções, } \\
\text { adequação com os critérios - proposição de uma } \\
\text { resposta. }\end{array}$ & $\begin{array}{l}\text { A determinação dos objetivos } \\
\text { Determinação dos resultados da intervenção das } \\
\text { autoridades públicas. Via moderada (orienta a } \\
\text { direção global) e via dura (estabelece características } \\
\text { como precisão, quantificação, clareza e prazos). }\end{array}$ \\
\hline
\end{tabular}

\footnotetext{
Tomada de decisão*

Criação de uma coalizão, legitimação de uma política escolhida - política efetiva de ação.
}

Aplicação da ação
Colocação em prática, gestão e administração,
produção de efeitos - impacto sobre o terreno.

\begin{abstract}
A avaliação dos resultados
Reação da aplicação da ação, julgamento sobre os efeitos, expressão - ação política ou ajustamento.
\end{abstract}

\section{Avaliação a priori}

Consideração dos meios a mobilizar, apreender os efeitos prováveis de uma política em todos os estágios de seu desenvolvimento.

\section{A implementação (mise en oeuvre)}

Mediatizada pelo direito (instrumentos difíceis de manejar), Mediatizada pelos atores - o jogo dos atores (sistema de pressão para os responsáveis políticos).

\section{A avaliação}

Atribui valor a um bem, organização ou ação. 1) sobre os efeitos da política:

Métodos de coleta e tratamento de informação. Considera os efeitos não procurados, os efeitos de ligação entre as políticas; analisa o impacto sem o meio.

2) Sobre o impacto e a eficiência da política: A compreensão do processo de implantação, fatores explicativos - nível e natureza dos meios engajados, performance da organização executora, teoria da mudança social implícita à política.

\section{Término da política ou da ação}

Fonte: Elaboração própria com base em Mény e Thoenig, Politiques Publiques, Paris, PUF, 1989, e Santo e Verrier, Le Management Public, Paris, PUF, 1993.

*Nota: Muller (2003) denomina “desenvolvimento do programa” a reunião das fases de formulação de uma solução ou de uma ação e tomada de decisão. 


\section{Conclusão}

Os últimos cinquenta anos do século XX assistiram à emergência e ao enfraquecimento do Estado Providência, que no pós-guerra foi o agente precursor da fabricação e implementação das políticas públicas. A onda neoliberal, que se seguiu a partir dos anos oitenta e noventa do século XX, trouxe uma redefinição do tamanho e do papel dos Estados nacionais bem como de seus processos de gestão e regulação: a mundialização da economia e novos arranjos políticos regionais passaram a exigir novas formas de regulação até transnacionais num contexto de complexidade crescente. Assistiu-se nos mais diversos países a processos semelhantes como: abertura de mercados, privatização em massa, bem como descentralização das políticas públicas e formas de participação crescentes de novos atores, entre outros. Às políticas setoriais, vieram se juntar as políticas transversais, exigindo regulações multiníveis (supranacional, nacional, regional e local).

Este artigo permitiu destacar algumas contribuições da análise sequencial de políticas públicas nas duas abordagens quanto à compreensão da ação do Estado no que se refere à análise de políticas públicas. Apesar de algumas especificidades apresentadas, é possível afirmar que as duas abordagens do modelo de análise sequencial apresentam mais semelhanças que diferenças, são mais complementares que antagônicas, visto que partiram da ação pública como um sistema composto de meios para concretizar as suas realizações, as quais deverão provocar impactos junto ao público-alvo, ou seja, os grupos sociais.

Observou-se que as duas abordagens aqui contempladas apresentaram interdependências e interações que marcaram suas trajetórias iniciais. Os autores que se aventuraram a traçar suas origens e percalços históricos, institucionais e doutrinários, com vistas a apreender as múltiplas influências e interações disciplinares e profissionalizantes, se depararam com trajetórias nacionais particulares, como no caso da França, mesmo que as influências mais marcantes venham dos países anglo-saxões, em especial, dos Estados Unidos.

Os quadros analíticos dessas abordagens se cruzam em aspectos fundamentais, apesar da clivagem entre elas ter sido sublinhada, em várias ocasiões, pelos seus autores. Daí o questionamento: até que ponto essas abordagens são diferentes ou as similitudes e complementaridades entre ambas são mais evidentes que as diferenças?

Quanto aos métodos, enquanto a abordagem da ciência política (políticas públicas) referiu-se a uma "caixa de ferramentas" para mencionar os aportes das ciências sociais à análise, a abordagem do management sublinhou o caráter estratégico da combinação dos instrumentos de gestão.

A diferença principal, todavia, diz respeito ao fato que a abordagem do management apresenta um caráter normativo e prescritivo, no qual os preceitos e normas de "boa governança" podem contribuir para o aperfeiçoamento da ação pública. Esse caráter prospectivo presente nessa análise foi rejeitado pela abordagem da ciência política.

Outra diferença refere-se aos principais expoentes e difusores das duas abordagens: enquanto a produção científica da abordagem da ciência política está centrada em acadêmicos, a abordagem do management tem sido cada vez mais veiculada por funcionários da alta função pública.

Todavia, a tendência é de uma complementaridade ainda maior entre a análise sequencial das duas abordagens, visto que atualmente métodos de gestão inovadores introduzidos pelo new public management estão se inserindo nas políticas públicas, as quais estão cada vez mais submetidas à avaliação, à mensuração da performance, aos métodos de coordenação e de articulação entre parceiros públicos e privados, aos parâmetros de benchmarker ${ }^{16}$ como indicadores de resultados consagrados pelos campeões de performance, ou seja, o caráter normativo e prospectivo das "boas práticas" está se impondo de forma generalizada às políticas públicas contemporâneas. 


\section{Referências}

BADIE, Bertrand; BIRNBAUM, Pierre. Sociologie de l'État, Paris, Grasset, 1982.

BARTOLLI, Anne. Le Management dans les organisations publiques, Paris, Dunod, 2006.

BEZÉS, Philippe. L'État et les savoirs managériaux : essor et développement de la gestion publique en France. pp 9-37 in 30 Ans de Réforme de l'État, expériences françaises et étrangères : stratégies et bilans, Paris, Dunod, 2005.

BENH, Robert. 0 Novo Paradigma da gestão pública e a busca da accountability democrática. Revista do Serviço Público, ano 49, n. 4, out.-dez. 1998.

BOUSSAGUET, Laurie; JACQUOT, Sophie; RAVINET, Pauline. Dictionnaire des Politiques Publiques. Paris, Presses de Science Po, 2006.

BRAUD, Philippe. Sociologie Politique, Paris, LGDJ, 2006.

CHEVALIER, Jacques. Politiques Publiques et changement social, in Revue Française d'administration publique. École Nationale d'administration, n. 115, 2005.

CROZIER, Michel. État Moderne, État Modeste, strategies pour un autre changement, Paris, Seuil, 1991.

DEFARGES, Philippe Moreau. La Gouvernance, Paris, Presses Universitaires de France, 2006.

GIBERT, Patrick. L'analyse de politique a la rescousse du management public ? ou la nécessaire hybridisation de deux approches que tout, sauf l'essentiel, sépare. In Revue Politiques et Management Public, v. 20, n. 1, mars 2002.

GIBERT, Patrick. Management Public, management de la puissance publique, in LACASSE, François et THOENIG, Jean Claude, L'Action Publique, Paris, L'Harmattan, 1996.

GAUDIN, Jean-Pierre. L'Action Publique, sociologie et politique, Paris, presses de Science Po/Dalloz, 2004.

GUILlaUmE, Henri; DUREAU, Guillaume; SILVENT, Franck. Gestion Publique, L'État et la Performance, Paris, Presses de Science Po et Dalloz, 2002.

JOBERT, Bruno; MULLER, Pierre. L'État en Action, Politiques Publiques et Corporatismes, Paris, Presses Universitaires de France, 1987.

LACASSE, François et Verrier, Pierre-Éric (direction). 30 Ans de Réforme de l'État, expériences françaises et étrangères : stratégies et bilans, Paris, Dunod, 2005.

LASCOUMES, Pierre; LE GALĖS, Patrick. Sociologie de l'Action Publique, Paris, Armand Colin, 2007.

LEFEBVRE, Alain et MEDA, Dominique. Faut-il bruler le modèle social français ?Paris, Seuil, 2006.

LE GALĖS, Patrick et THATCHER Mark (direction). Les Réseaux de Politique Publique. Débat autour des policy networks. Paris, L'Harmattan, 1995.

MASSARDIER, Gilles. Politiques et Action Publiques, Paris, Armand Colin, 2003.

MATHESON, Alex (entretien). Après 20 ans de modernisation de la gestion publique, où est-on ? in Revue Problemès economiques, $\mathrm{n}$ 2907, 27 septembre de 2006, La documentation Française.

MENY, Yves; THOENIG, Jean-Claude. Politiques Publiques, Paris, Presses Universitaires de France, 1989.

MINTZBERG, Henry. Le Management, voyage au centre des organisations, Paris, Eyrolles, 2004.

MORDACQ, Frank. La loi Organique relative aux lois de finances, féderatrice des aspirations démocratiques, in LACASSE, François et Verrier, Pierre-Éric (direction) 30 Ans de Réforme de l'État, expériences françaises et étrangères : startégies et bilans, Paris, Dunod, 2005.

MULLER, Pierre. Les Politiques Publiques, Paris, Presses Universitaires de France, 5 ème édition mise en jour 2003.

POLIT, Christophe. La réforme de la gestion publique est-elle " exportable " ? in Revue Problemès economiques, n 2907, 27 septembre de 2006, La documentation Française. 
ROSANVALLON, Pierre. La crise de l'État Providence, Paris, Seuil, 1981.

SANTO, Viriato Manuel et VERRIER, Pierre Eric, Le Management Public, Paris, 1993.

SFEZ, Lucien. Critique de la Décision, Paris, Presse de la Fondation Nationale de Science Politique, 1992.

THIETART, Raymond-Alain. Méthodes de Recherche en Management, Paris, Dunod, 2007.

TROSA, Sylvie. Vers un Management Post-Bureaucratique. La réforme de l'État une reforme de la société. Paris, L'Harmattan, 2006.

NOTAS:

${ }^{1}$ A abordagem da ciência política inclui a sociologia política.

${ }^{2}$ Traduziu-se a abordagem francesa management public, ou gestion publique, por gestão pública. Essa opção terminológica pareceu mais adequada ao texto em português visto que alguns autores franceses utilizam indistintamente uma ou outra expressão a exemplo de Muller (2003).

${ }^{3}$ A abordagem do management foi traduzida por gestão, os dois termos serão utilizados ao longo do presente trabalho.

${ }^{4}$ O primeiro manual sobre análise de políticas públicas na França foi escrito por um cientista político (Yves Mény) e um sociólogo (Jean Claude Thoenig).

${ }^{5}$ Ambos publicados pela Presses Universitaires de France.

${ }^{6}$ Vale ressaltar que Patrick Gibert classifica o management público em duas abordagens: management em sentido restrito, que se focaliza nas organizações públicas, e management em sentido amplo, que contempla tanto as organizações públicas quanto a análise de políticas públicas. Essa última abordagem se subdivide em duas subcorrentes: (1) uma subcorrente acadêmica, dirigida a um maior conhecimento da ação pública, mas sem pretensão de estabelecer normas e prescrições para melhorar a ação do governo e (2) uma subcorrente que visa contribuir para uma melhor performance da ação pública mediante prescrições para o governo, desempenhando o papel de "conselheiro do príncipe" (Conseiller du Prince, expressão utilizada por Gibert mediante citação de Wildavsky).

7 Segundo Bezés (2005), o Social Science Researche Council, criado em 1923, foi o primeiro organismo de financiamento de pesquisa voltado para análises da sociedade e da ação pública. Essa organização foi seguida por fundações privadas como Rockefeller, Carnegie e Ford.

${ }^{8}$ O Estado Providência pode ser compreendido em dois principais sentidos, no sentido de Estado intervencionista, que se institucionalizou após a Segunda Guerra Mundial, e no sentido de Estado que intervém para assegurar as funções de solidariedade fundadas nos direitos dos cidadãos e trabalhadores (Merrien, 2007, p. 3).

${ }^{9}$ De acordo com Bertrand Badie e Pierre Birnbaum, Sociologie de l'État (Paris, Grasset, 1982), o Estado esteve fortemente presente na França desde o século XVII através da coleta de impostos, do exército, entre outros, exercendo mesmo o controle das consciências através da Igreja, "Église Gallicane", das universidades e do ensino no século XVIII.

${ }^{10}$ L'État et les savoirs managériaux : essor et développement de la gestion publique en France, in François Lacasse et Pierre-Eic Verrier 30 ans de réforme de l'État, expériences françaises et étrangères : stratégies et bilan, Paris Dunod, 2005, p 9-37.

${ }^{11}$ O Cesmap foi criado em 1970, após a constituição da Direction de l'Enseignement Supérieur Administratif du Ministère des Postes et Telecommunications e com o apoio da Escola de Administração do PTT - ENSPTT. O CSFM foi criado em 1971 pela iniciativa comum de sete grandes escolas de engenharia reunidas pela École Nationale de l'Administration (ENA), com o apoio da Fondation Nationale pour l'Enseignement et la Gestion des Entreprises (FNEGE).

12 O ensino universitário do management no nível de terceiro ciclo só teve início na França em 1985 com a implementação de um Diploma de Estudos Aprofundados em "gestão pública" da Université de Paris I conjuntamente com a Université de Caen.

${ }^{13}$ Segundo Bezés (2005), a interrupção do recrutamento de contratações para atuar nas grandes escolas de gestão e nas instituições como Cesmap e CSFM fragilizou a ação dessas instituições.

${ }^{14}$ Entende-se por boas práticas a reunião de novas idéias de gestão ou novas tecnologias de gestão que guiam as reformas da gestão públicas nos países. Essa expressão tem sido amplamente difundida pela OCDE.

${ }^{15}$ O livro de Charles Jones An Introduction to the Study of Public Policy, 1970, adotou a análise da política como uma sequência de decisões. Esse método de análise exerceu forte influência nos estudos de políticas públicas subsequentes.

${ }^{16}$ Benchmarking significa limite de fronteiras e de territórios ou posicionamento relativo. Todavia constitui a partir de 1950 uma técnica de marketing empresarial que consiste em encontrar e estudar aqueles que realizam uma tarefa ou processo com maior nível de performance para, mediante adaptação, transferir esse processo à sua empresa (Lefebvre, Meda, 2006, segundo Laurant Maruani, professor de marketing na HEC Paris e diretor de l'Institut des Stratégies). 